\title{
Uma análise da produção científica da área de contabilidade governamental nos periódicos que utilizam o SEER e o SciELO
}

\author{
An analysis of scientific production in the area of governmental accounting journals using the \\ SEER and SCIELO
}

\author{
Fabia Jaiany Viana de Souza \\ fabiajaiany@yahoo.com.br
} UFRN

\author{
Mauricio Corrêa da Silva \\ prof.mauriciocsilva@gmail.com \\ UFRN
}

\author{
Aneide Oliveira Araújo \\ aneide@ufrnet.br \\ UFRN
}

\begin{abstract}
Resumo: Os estudos bibliométricos, inicialmente, eram voltados para a medida da quantidade de edições e exemplares de livros, bem como sua quantidade de palavras, depois expandiu para outros formatos, como artigos de periódicos e outros tipos de documentos e a produtividade de autores e o estudo de citações. Esta pesquisa tem como objetivo geral analisar como está atualmente a situação da produção científica da contabilidade aplicada ao setor público nos periódicos que utilizam o SEER e o SciELO. Foram utilizadas as pesquisas descritiva, bibliográfica e qualitativa. Os resultados revelaram que nas 564 edições analisadas foram encontrados 152 artigos relacionados com a contabilidade governamental. Os periódicos que mais publicaram dos consultados foram: Contabilidade, Gestão e Governança com 19 artigos, Revista de Administração Pública com 17, Revista Universo Contábil com 11 e Enfoque: Reflexão Contábil com 10 publicações. Houve o predomínio de autores professores do sexo masculino, com titulação de doutor que mais publicaram. A Universidade de São Paulo (USP) seguida da Universidade de Brasília (UnB) foram as instituições que apresentaram o maior número de autores com artigos publicados. Quanto às referências, foram mais utilizadas as brasileiras e que os periódicos que apresentam o maior número de referências estrangeiras em seus artigos são as que possuem melhor classificação no Qualis da CAPES.
\end{abstract}

Palavras-chave: Contabilidade Governamental. Produção Científica. Estudo Bibliométrico.

\begin{abstract}
The bibliometric studies were initially aimed to measure the number of editions and copies of books, as well as the quantity of words, then expanded to other formats such as journal articles and other documents and productivity of authors and the study of citations. This research aims at analyzing the situation as is currently the scientific production of accounting applied to the public sector in the journals that use SEER and SciELO. We used descriptive research, literature and qualitative. The results revealed that the 564 issues analyzed were found 152 articles related to governmental accounting. The journals that published most of the respondents were: Accounting, Management and Governance with 19 articles, Journal of Public Administration at 17, with 11 Magazine Universe Accounting and Focus: Accounting Reflection with 10 posts. There was a predominance of male teachers authors, with titles published over the doctor. The University of São Paulo (USP) followed by the University of Brasilia (UNB) were the institutions that had the largest number of authors of published articles.
\end{abstract}


As for the references, the Brazilians were most used and that the journals that have the largest number of foreign references in his articles are the ones with better ranking in the CAPES Qualis.

Keywords: Government Accounting. Scientific Production. Bibliometric study.

Artigo recebido em: 20.01.2013; Aceito em: 05.04.2013

\section{INTRODUÇÃO}

A comunicação pode ser considerada como elemento indispensável para a atividade científica, tendo em vista que sem ela, não existiria ciência e não se poderiam somar os esforços individuais dos membros das comunidades científicas. A comunicação científica, entendida como o conjunto de atividades associadas à disseminação e ao uso da informação, é importante para a aceitação do que é produzido cientificamente como constituinte do conhecimento científico (OLIVEIRA, 2002).

Em virtude da expansão acelerada da comunicação científica em contabilidade, diversas pesquisas desenvolvidas até o momento, tiveram como escopo de investigação a qualidade e o rigor científico, as estratégias metodológicas, o conteúdo e a forma, a autoria e as referências bibliográficas da produção científica da área de ciências contábeis no Brasil (SOUZA et al., 2008).

Os estudos que focam a produção científica em contabilidade no Brasil têm sido mais frequentes nos últimos anos, embora, ainda em pequeno número. Os trabalhos encontrados são, em regra, orientados pela bibliometria, que consiste na avaliação quantitativa de artigos, relatórios científicos, teses, dissertações etc. (THEÓPHILO; IUDÍCIBUS, 2005).

Souza et al. (2008, p.2) afirmam que "pode-se considerar que entre os principais instrumentos e veículos de divulgação da produção científica nacional estão os periódicos brasileiros de contabilidade considerados científicos".

Ao mesmo tempo em que ocorre esse desenvolvimento nos meios de divulgação da produção científica, observa-se que a contabilidade brasileira tem passado por grandes mudanças, em virtude da convergência com as normas internacionais e essas modificações, também, incluem a contabilidade aplicada ao setor público.

A contabilidade aplicada ao setor público está passando por diversas mudanças, mesmo antes da revogação da Lei $\mathrm{n}^{\circ}$ 4.320, de 17 de março de 1964 e da nova edição da lei de finanças públicas, que se encontra em estudos e tramitação no Congresso Nacional. A Portaria do Ministro da Fazenda n ${ }^{\circ} 184$, de 25 de agosto de 2008 estabeleceu diretrizes a serem observadas no setor público, quanto aos procedimentos, práticas, elaboração e divulgação das demonstrações contábeis, de forma a torná-los convergentes com as Normas Internacionais de Contabilidade Aplicadas ao Setor Público. Desse modo, observa-se que existem muitas pesquisas a serem realizadas com o intuito de difundir tais procedimentos.

A produção científica na área da contabilidade aplicada ao setor público foi discutida por Piscitelli, Timbó e Rosa (2002) ao analisarem publicações diversas e por Reis et al. (2007) na 'análise de artigos publicados em três congressos considerados relevantes no meio acadêmico nacional: o Encontro Nacional da Associação de Pós-Graduação em Administração (EnANPAD), o Congresso Brasileiro de Custos e o Congresso de Controladoria e Contabilidade da Universidade de São Paulo (USP). Nas referidas análises foram observados um reduzido número de publicações sobre essa área de estudo da contabilidade. 
Neste sentido, identificar como está atualmente a produção científica na contabilidade aplicada ao setor público é importante, tanto para os pesquisadores desta área, como também para os órgãos normativos. A participação dos pesquisadores acadêmicos pode e deve contribuir no processo do aperfeiçoamento normativo que orienta a contabilidade aplicada ao setor público. O conhecimento dos periódicos que mais divulgam produções científicas, das instituições de ensino superior que possuem mais autores, das palavras-chaves mais utilizadas etc., sobre a contabilidade aplicada ao setor público serve para incentivar novos pesquisadores.

Neste contexto, emerge a seguinte questão desta pesquisa: Como está atualmente a situação da produção científica da contabilidade aplicada ao setor público nos periódicos que utilizam o SEER e o SciELO?

Esta pesquisa tem como objetivo geral analisar como está atualmente a situação da produção científica da contabilidade aplicada ao setor público nos periódicos que utilizam o SEER e o SciELO.

A relevância da pesquisa é traçar um perfil geral sobre a produção científica da contabilidade aplicada ao setor público, a partir dos artigos científicos publicados nos periódicos de livre acesso na Internet, com a perspectiva de fomentar mais estudos nesta área do conhecimento.

A pesquisa é constituída por cinco tópicos: este primeiro denominado introdução fornece uma visão geral a respeito da pesquisa. O segundo compreende o embasamento do estudo, constituído da apresentação dos conceitos da literatura existentes acerca do estudo da produção científica, do estudo bibliométrico e da contabilidade aplicada ao setor público. O terceiro trata da metodologia que norteará a pesquisa. O quarto apresenta os resultados da pesquisa. O quinto considerações finais, recomendação e conclusão.

\section{REFERENCIAL TEÓRICO}

Este tópico contém uma exposição dos principais aspectos conceituais necessários à compreensão do artigo. No primeiro momento, apresentam-se as abordagens conceituais sobre produção científica; em seguida, discute-se a respeito do estudo bibliométrico, e por fim, são apresentados alguns conceitos relacionados à contabilidade aplicada ao setor público.

\subsection{PRODUÇÃO CIENTÍFICA}

A produção científica, de acordo com Santana (2004), tem o objetivo de fornecer explicações sobre o porquê dos fenômenos que ocorrem na evolução da sociedade. Esse é um posicionamento fácil de ser observado ao se analisar o desenvolvimento do conhecimento científico e ao observar que ele ocorre devido a um aglomerado de pesquisas, descobertas e análises que se acumulam com o passar dos anos e formam um arcabouço empírico e conceitual sobre os diversos conhecimentos classificados como ciência.

Nesse contexto, Leite Filho e Siqueira (2007) caracterizam a ciência como sendo o resultado do trabalho desenvolvido por estudiosos, pesquisadores, professores, alunos, ou seja, por um conjunto de pessoas que tem o objetivo comum de procurar explicações para os fenômenos que ocorrem ao seu redor e que estão inseridos dentro dos seus objetos de estudo.

Sendo assim, a produção científica pode ser considerada como um importante meio de veiculação do conhecimento na modalidade escrita, proporcionando o desenvolvimento da ciência, da tecnologia, a abertura de novas linhas de estudo e pesquisa, sobretudo no meio acadêmico (NORONHA; KIYOTANI; JUANES, 2002).

Haidar (2008, p.4) afirma que "a produção e os pesquisadores utilizam diversos meios de comunicação gerais e científicos, sendo que o mais utilizado é a publicação em veículos 
científicos, principalmente em periódicos, por apresentar maior conceito na comunidade científica".

O artigo de periódico é um trabalho técnico ou científico que visa principalmente a maior agilidade na divulgação do assunto tratado, seguindo as normas de publicação do periódico a que se destina (BEUREN et al., 2003).

Segundo Oliveira (2002, p.69), a produção científica, divulgada em forma de artigos publicados em periódicos, é importante sob vários aspectos:

\footnotetext{
"os artigos podem ser colecionados, classificados, catalogados e reproduzidos infinitamente; os cientistas não publicam livros nem defendem teses e dissertações com frequência, além do que a agilidade na circulação destes veículos e, consequentemente, da informação contida neles, principalmente quando se trata de teses e dissertações, é mais lenta; os artigos de periódicos atingem, mais velozmente, que teses e dissertações, um público maior, servem como fonte de bibliografia e contribuem para a atualização dos que os leem”.
}

Leite Filho e Siqueira (2007) destacam que a veiculação da produção científica em periódicos, no contexto internacional e nacional, demonstra ser, um dos principais meios de comunicação escrita do conhecimento científico, sendo utilizado como parâmetro principal do potencial científico de uma nação.

Assim, observa-se que a produção científica é na atualidade uma das maiores ferramentas de desenvolvimento de uma sociedade, sendo utilizada para a busca dos questionamentos que a população julga como fundamentais para o bom convívio em grupo. Associado a esse fato, tem-se que os artigos publicados em periódicos são um dos atores principais para a se atingir esse objetivo da comunicação científica, em virtude de seus resultados serem apresentados para a população de maneira mais rápida e por atingirem um grupo maior de pessoas, devido à facilidade de divulgação e circulação dos periódicos.

\subsection{ESTUDO BIBLIOMÉTRICO}

A bibliometria pode ser entendida como ramo da ciência da informação, que mesmo sem restringir seu universo de pesquisa aos domínios da produção científica convencional, prioriza esse tipo de literatura como objeto (ALVARENGA, 1998). Ainda de acordo com o referido autor, as informações decorrentes das pesquisas bibliométricas relacionados à quantificação da literatura, aos autores, aos textos e às possíveis redes de relações estabelecidas entre os mesmos, possibilitam a constituição de insumos que revelam ângulos diferenciados sobre a produção científica analisada.

Segundo Leite Filho e Siqueira (2007), o estudo bibliométrico é uma da formas de se avaliar a produção científica em determinada área do conhecimento, tendo como objeto o estudo das publicações. A bibliometria, de acordo com Rosa et al. (2010), se encarrega de estudar e avaliar as atividades de produção e comunicação científica.

Araújo (2006) esclarece que os estudos bibliométricos, inicialmente, eram voltados para a medida da quantidade de edições e exemplares de livros, bem como sua quantidade de palavras, depois expandiu para outros formatos, como artigos de periódicos e outros tipos de documentos e a produtividade de autores e o estudo de citações.

Dessa forma, pode-se conceituar o estudo bibliométrico como sendo um ramo da ciência que tem como objetivo a investigação das publicações científicas, no sentido de tentar levantar as principais características da comunicação cientifica pesquisada.

Os estudos bibliométricos a seguir, analisaram as pesquisas contábeis: Oliveira (2002) analisou as características dos periódicos nacionais de contabilidade. Santana (2004) estudou a pesquisa 
de contabilidade social no Brasil de 1990 a 2003. Cardoso et al. (2005) analisaram a distribuição, as características metodológicas, a evolução e a temática das publicações científicas em contabilidade, assim como a produção de seus autores no período entre 1990 e 2003, nas revistas nacionais classificadas com conceito "A" pela CAPES.

Ponte et al. (2007) estudaram as metodologias e técnicas de pesquisa adotadas nos artigos publicados no Brasil nas áreas de administração e contabilidade sobre o modelo Balanced Scorecard (BSC). Souza et al. (2008) analisaram as Instituições de Ensino Superior (IES) da área de ciências contábeis e seus pesquisadores por meio de sua produção científica em 657 artigos de congressos da área. Barbosa e Barros (2010) pesquisaram o perfil dos autores na produção científica em contabilidade: o caso do congresso USP de controladoria e contabilidade e do congresso ANPCONT.

Perdigão, Niyama e Santana (2010) analisaram as características da revista de Contabilidade, Gestão e Governança, no período de 1998 a 2009. Barbosa, Quintana e Machado (2011) verificaram a produção científica sobre os fluxos de caixa e a Demonstração dos Fluxos de Caixa (DFC), na Revista de Contabilidade \& Finanças da Universidade de São Paulo, no período de 1989 a 2009.

Esses estudos são interessantes para a área contábil porque permitem conhecer o perfil das publicações científicas, atualmente desenvolvidas, com a perspectiva de aperfeiçoar esses estudos e de provocar discussões sobre os temas que estão sendo mais estudados pelos pesquisadores.

\subsection{CONTABILIDADE APLICADA AO SETOR PÚBLICO}

A contabilidade pública ou contabilidade governamental ou ainda a contabilidade aplicada ao setor público apresenta diferentes conceitos, entre eles: Silva (2002) afirma que a contabilidade pública é uma especialização da contabilidade, voltada para o estudo e análise dos atos e fatos que ocorrem na administração pública e que possui como objeto o patrimônio público.

Piscitelli e Timbó (2010) conceituam a contabilidade do setor público como o ramo da ciência contábil aplicável as entidades de direito público e que apresenta como campo de aplicação as aziendas ou entidades públicas, integrantes da estrutura da administração e sujeitas a seu controle.

Para Bezerra Filho (2004), a contabilidade governamental pode ser definida como sendo um ramo da ciência contábil que controla o patrimônio público, evidenciando as variações e os consequentes resultados, inclusive sociais, decorrentes dos atos e fatos de natureza orçamentária, financeira e patrimonial nas entidades de administração pública.

Kohama (2003) considera esse ramo da contabilidade como um dos mais complexos, tendo em vista que é estruturado tendo como base quatro sistemas inter-relacionados: orçamentário, financeiro, patrimonial e de compensação e tem como finalidade captar, registrar, acumular, resumir e interpretar todos os fenômenos que afetem as situações orçamentárias, financeiras e patrimoniais das entidades de direito público.

Reis e Machado Júnior (2010) entendem a contabilidade pública como área capaz de elaborar, com oportunidade e fidedignidade, relatórios que tenham o objetivo de servir de base para o processo de tomada de decisão da administração e que demonstrem os efeitos produzidos por esses atos de gestão no patrimônio da entidade.

Diante desse contexto, observa-se que a contabilidade pública (governamental ou contabilidade aplicada ao setor público) pode ser conceituada de forma simplificada como o ramo da Ciência Contábil responsável pelo controle do patrimônio público das entidades do setor público. Ressalta-se ainda, que essa especialização da contabilidade possui papel fundamental para o 
processo de gestão dessas entidades, uma vez que permite que a administração analise e tome decisões que visem melhorar a arrecadação de suas receitas e a programação de suas despesas.

\section{METODOLOGIA}

Beuren et al. (2003) sugerem que a pesquisa em contabilidade seja delineada quanto aos objetivos, procedimentos e abordagem do problema. Neste sentido, este estudo caracteriza-se como pesquisa descritiva (objetivos), bibliográfica (procedimentos) e qualitativa (abordagem do problema).

Os autores acima esclarecem que a pesquisa descritiva configura-se como um estudo intermediário entre a pesquisa exploratória e a explicativa e neste contexto, descrever significa identificar, relatar, comparar, entre outros aspectos. No caso, são identificados e relatados dados sobre a produção científica da contabilidade governamental em periódicos.

A estratégia da pesquisa bibliográfica, segundo Martins e Theóphilo (2009) é necessária para a condução de qualquer pesquisa científica, haja vista que procura explicar e discutir um assunto, tema ou problema com base em referências publicadas em livros, periódicos, revistas, enciclopédias, dicionários, jornais etc.

A análise qualitativa, segundo Beuren et al. (2003), visa destacar características não observadas por meio de um estudo quantitativo e assim concebem-se análises mais profundas em relação ao fenômeno que está sendo estudado.

Para atingir o objetivo da pesquisa, foi usada como amostra intencional os periódicos que utilizam o SEER e o SciELO e que possuem acesso livre na Internet. Foram consultadas todas as edições disponibilizadas, no período de 01 de outubro até 31 de dezembro de 2011. O total das edições analisadas foram 564. A quantidade de artigos por edições variaram entre 5 a 8 artigos por edição. Se considerar uma média de 5 artigos por edição, chega-se ao número de 2.820 artigos consultados para a elaboração desse estudo.

O Sistema Eletrônico de Editoração de Revistas (SEER) é um software desenvolvido para a construção e gestão de uma publicação periódica eletrônica. Ele contempla ações essenciais à automação das atividades de editoração de periódicos científicos. O Instituto Brasileiro de Informação em Ciência e Tecnologia (IBICT) foi o responsável pela tradução e customização do sistema que teve como base o software elaborado pelo Public Knowledge Project (Open Journal Systems) da Universidade British Columbia. A utilização do SEER como ferramenta para o processo de editoração de revistas permite uma maior rapidez no fluxo das informações (IBICT, 2011).

O Scientific Electronic Library Online - SciELO (Biblioteca Científica Eletrônica em Linha) é um modelo que foi desenvolvido para a publicação eletrônica cooperativa de periódicos científicos na Internet. Ele foi elaborado com a finalidade de responder as necessidades da comunicação científica nos países em desenvolvimento e particularmente na América Latina e Caribe. O SciELO é resultado da cooperação entre a Fundação de Amparo à Pesquisa do Estado de São Paulo (FAPESP), Centro Latino-Americano e do Caribe de Informação em Ciências da Saúde (BIREME), instituições nacionais e internacionais relacionadas com a comunicação científica e editores científicos. Desde Junho de 1998 o projeto funciona regularmente, incorporando novos títulos de periódicos e expandindo sua operação para outros países. A partir de 2002, o projeto passou a contar com o apoio do CNPq - Conselho Nacional de Desenvolvimento Científico e Tecnológico (SciELO, 2011).

A coleta de dados do artigo foi desenvolvida, inicialmente, com o levantamento de todas os periódicos de contabilidade e administração que utilizam o SEER e o SciELO e foi realizada a seleção dos mesmos (Quadro 1). Em seguida, foi consultado o sítio eletrônico de cada revista para verificar a existência de alguma publicação relacionada com a contabilidade 
governamental. Para constatar se os artigos tinham relação com esse tema, era consultado em cada publicação, o resumo e as palavras-chaves.

Após a coleta de dados, as informações coletadas foram trabalhadas em planilhas do Microsoft Excel.

Vale ressaltar, que a limitação da pesquisa reside no fato de que apenas foram consultados os artigos que estavam disponibilizados nos sítios de cada periódico, não sendo consultadas todas as edições desde a criação de alguns periódicos, como exemplo, a Revista de Contabilidade \& Finanças, que apenas passou a utilizar o SciELO a partir do número 25 do ano 2001 e a Revista de Administração Pública que apresenta os artigos a partir de 2006.

\section{RESULTADOS DA PESQUISA E ANÁLISES}

\subsection{Revistas que utilizam o SEER e o SciELO}

A Tabela 1 apresenta as revistas que utilizam o SEER e SciELO que foram pesquisadas, suas instituições de ensino vinculadas, a sua classificação no Qualis CAPES, os números de edições analisadas e o número de artigos relacionados à contabilidade governamental que foram encontrados em cada periódico.

Tabela 1 - Revistas que utilizam o SEER e o SciELO que foram pesquisadas

\begin{tabular}{|c|c|c|c|c|c|c|}
\hline Nome do Periódico & Instituição & $\begin{array}{c}\text { Classificação } \\
\text { no Qualis } \\
\text { CAPES }\end{array}$ & $\begin{array}{l}\text { Número de } \\
\text { edições } \\
\text { analisadas }\end{array}$ & $\begin{array}{c}\text { Número de } \\
\text { artigos sobre } \\
\text { contabilidade } \\
\text { governamental }\end{array}$ & SEER & SciELO \\
\hline $\begin{array}{l}\text { Revista de } \\
\text { Administração Pública }\end{array}$ & FGV & A2 & 37 & 17 & & $\mathrm{X}$ \\
\hline RAE Eletrônica & FGV/EAESP & B1 & 18 & 2 & & $\mathrm{X}$ \\
\hline $\begin{array}{l}\text { Revista de } \\
\text { Administração } \\
\text { Contemporânea } \\
\end{array}$ & ANPAD & B1 & 69 & 6 & & $\mathrm{X}$ \\
\hline $\begin{array}{l}\text { Revista de } \\
\text { Administração } \\
\text { Mackenzie - RAM } \\
\end{array}$ & MACKENZIE & B1 & 17 & 0 & & $\mathrm{X}$ \\
\hline $\begin{array}{l}\text { Revista de } \\
\text { Contabilidade \& } \\
\text { Finanças } \\
\end{array}$ & FEA-USP & B1 & 36 & 5 & & $X$ \\
\hline $\begin{array}{l}\text { Revista de } \\
\text { Contabilidade e } \\
\text { Organizações } \\
\end{array}$ & FEA-RP & B3 & 12 & 5 & $X$ & \\
\hline $\begin{array}{l}\text { Revista } \\
\text { Contemporânea de } \\
\text { Contabilidade } \\
\end{array}$ & UFSC & B3 & 16 & 8 & $X$ & \\
\hline $\begin{array}{l}\text { Revista de Educação e } \\
\text { Pesquisa em } \\
\text { Contabilidade }\end{array}$ & $\mathrm{CFC}$ & B3 & 15 & 9 & $\mathrm{X}$ & \\
\hline $\begin{array}{l}\text { Contabilidade Vista \& } \\
\text { Revista }\end{array}$ & UFMG & B3 & 61 & 14 & $\mathrm{X}$ & \\
\hline $\begin{array}{l}\text { Revista Universo } \\
\text { Contábil }\end{array}$ & FURB & B3 & 25 & 11 & $X$ & \\
\hline $\begin{array}{l}\text { Contextus - Revista } \\
\text { Contemporânea de } \\
\text { Economia e Gestão }\end{array}$ & UFC & B4 & 17 & 1 & $\mathrm{X}$ & \\
\hline Pensar Contábil & CRC - RJ & B4 & 26 & 7 & $\mathrm{X}$ & \\
\hline
\end{tabular}

R. Cont. Ufba, Salvador-Ba, v. 7, n. 2, p. 22-37, maio-agosto 2013 


\begin{tabular}{|c|c|c|c|c|c|}
\hline Revista Análise & PUC-RS & B4 & 13 & 3 & $\mathrm{X}$ \\
\hline $\begin{array}{l}\text { Revista de } \\
\text { Contabilidade do } \\
\text { Mestrado em Ciências } \\
\text { Contábeis da UERJ }\end{array}$ & UERJ & B4 & 20 & 8 & $\mathrm{X}$ \\
\hline $\begin{array}{l}\text { Revista de Informação } \\
\text { Contábil }\end{array}$ & UFPE & B4 & 17 & 7 & $\mathrm{X}$ \\
\hline $\begin{array}{l}\text { Revista Economia \& } \\
\text { Gestão }\end{array}$ & PUC - MG & B4 & 24 & 4 & $\mathrm{X}$ \\
\hline $\begin{array}{l}\text { Revista Produção } \\
\text { Online }\end{array}$ & UFSC & B4 & 37 & 1 & $\mathrm{X}$ \\
\hline $\begin{array}{l}\text { Enfoque: Reflexão } \\
\text { Contábil }\end{array}$ & UEM & B5 & 19 & 10 & $\mathrm{X}$ \\
\hline $\begin{array}{l}\text { Contabilidade, Gestão } \\
\text { e Governança }\end{array}$ & UnB & $\mathrm{C}$ & 31 & 19 & $\mathrm{X}$ \\
\hline Contexto & UFRGS & $\mathrm{C}$ & 20 & 7 & $\mathrm{X}$ \\
\hline $\begin{array}{lr}\text { Ciências } & \text { Sociais } \\
\text { Aplicadas em } & \text { Revista }\end{array}$ & UNIOESTE & $\mathrm{C}$ & 8 & 1 & $\mathrm{X}$ \\
\hline $\begin{array}{l}\text { Revista Ambiente } \\
\text { Contábil }\end{array}$ & UFRN & $\mathrm{C}$ & 6 & 3 & $\mathrm{X}$ \\
\hline $\begin{array}{l}\text { Revista de } \\
\text { Contabilidade da } \\
\text { UFBA }\end{array}$ & UFBA & $\mathrm{C}$ & 12 & 4 & $\mathrm{X}$ \\
\hline $\begin{array}{l}\text { Revista Gestão } \\
\text { Organizacional }\end{array}$ & UNOCHAPECÓ & $\mathrm{C}$ & 8 & 0 & $\mathrm{X}$ \\
\hline \multicolumn{3}{|c|}{ Totais } & 564 & 152 & \\
\hline
\end{tabular}

Fonte: Elaborada pelos autores.

Observa-se pela Tabela 1 que foram analisadas 564 edições das revistas que utilizam o SEER e o SciELO. Dessas, as que tiveram o maior número de edições consultadas foram: Revista de Administração Contemporânea e Contabilidade Vista \& Revista com respectivamente 69 e 61 edições pesquisadas. Percebe-se ainda, que 152 artigos relacionados à contabilidade governamental foram encontrados nas 564 edições analisadas. A Revista Contabilidade, Gestão e Governança foi responsável por 19 artigos, sendo a revista que mais publicou nessa temática dentre os periódicos consultados. Ressalta-se que a Revista Gestão Organizacional e a Revista de Administração Mackenzie não apresentaram em nenhuma de suas edições um artigo sobre essa área de estudo.

A Tabela 2 apresenta a quantidade de autores e de artigos.

Tabela 2 - Distribuição de autores por artigo

\begin{tabular}{c|c|c}
\hline Quantidade de autores & Quantidade de artigos & \% \\
\hline 1 autor & 28 & 18,42 \\
\hline 2 autores & 52 & 34,21 \\
\hline 3 autores & 38 & 25,00 \\
\hline 4 autores & 27 & 17,76 \\
\hline 5 autores & 7 & 4,61 \\
\hline Total & $\mathbf{1 5 2}$ & $\mathbf{1 0 0}$ \\
\hline
\end{tabular}

Fonte: Elaborada pelos autores.

Com relação à quantidade de autores por artigo, apresentada na Tabela 2, não ficou evidenciado uma concentração de grande número de autores por artigo, visto que, apenas $22,37 \%$ dos artigos tiveram entre 4 e 5 autores, e a maioria, 77,63\% ficou entre 1 e 3 autores. Acrescenta-se às 
informações da Tabela 2, que no total dos 152 artigos houve 308 autores, sendo que, na média obteve-se 2,02 autores por artigo.

A Tabela 3 apresenta o gênero dos autores dos artigos encontrados.

Tabela 3 - Distribuição dos autores quanto ao gênero

\begin{tabular}{c|c|c}
\hline Gênero & $\mathbf{N}^{\mathbf{o}}$ de Autores & \% \\
\hline Feminino & 87 & 28,25 \\
\hline Masculino & 221 & 71,75 \\
\hline TOTAL & $\mathbf{3 0 8}$ & $\mathbf{1 0 0}$ \\
\hline
\end{tabular}

Fonte: Elaborada pelos autores.

Do universo de 308 autores distribuídos entre os 152 artigos, analisou-se também o gênero (Tabela 3) e foi observado que 221 eram do sexo masculino e 87 do sexo feminino, ou seja, $71,75 \%$ dos autores são homens e $28,25 \%$ mulheres. Situação que demonstra que nas revistas analisadas a produção foi dominada por autores do sexo masculino.

A Tabela 4 é responsável por apresentar a classificação dos autores quanto ao nível de formação em oito categorias.

Tabela 4 - Nível de formação dos autores

\begin{tabular}{c|c|c}
\hline Grau de formação & Quantidade de autores & \% \\
\hline Graduando & 10 & 3,25 \\
\hline Graduado & 7 & 2,27 \\
\hline Especialista & 19 & 6,17 \\
\hline Mestrando & 58 & 18,83 \\
\hline Mestre & 73 & 23,70 \\
\hline Doutorando & 28 & 9,09 \\
\hline Doutor & 109 & 35,39 \\
\hline Pós-doutor & 4 & 1,30 \\
\hline TOTAL & $\mathbf{3 0 8}$ & $\mathbf{1 0 0}$ \\
\hline
\end{tabular}

Fonte: Elaborada pelos autores.

Como pode ser constatado com a observação da Tabela 4, a produção científica dos periódicos analisados foi dominada por autores com nível de pós-graduação stricto sensu e estudantes desse nível de formação, que representou 88,31\%, com destaque ao nível de doutorado, que apresentou 109 autores com essa titulação. Esse resultado pode ser justificado pelo fato da produção científica ser um dos aspectos de avaliação dos programas de pós-graduação stricto sensu, situação que acarreta a necessidade desses programas intensificarem a produção de comunicação científica no país.

A vinculação institucional dos autores foi outra análise realizada que pode ser verificada na Tabela 5.

Tabela 5 - As quinze instituições de ensino superior com maior número de autores com artigos publicados

\begin{tabular}{c|c}
\hline Instituições de Ensino Superior & Quantidade de autores \\
\hline USP & 26 \\
\hline UNB & 22 \\
\hline \multicolumn{2}{|c|}{ R. Cont. Ufba, Salvador-Ba, v. 7, n. 2, p. 22-37, maio-agosto 2013 }
\end{tabular}




\begin{tabular}{c|c}
\hline UERJ & 21 \\
\hline UFPE & 17 \\
\hline UFSC & 13 \\
\hline UFRN & 11 \\
\hline UFRJ & 10 \\
\hline UFMG & 10 \\
\hline UFRGS & 8 \\
\hline UFPB & 6 \\
\hline UFU & 6 \\
\hline FGV & 5 \\
\hline UFBA & 4 \\
\hline UEM & 4 \\
\hline UFCG & 4 \\
\hline
\end{tabular}

Fonte: Elaborada pelos autores.

Nos 152 artigos analisados, observou-se que os 308 autores foram provenientes de 43 instituições diferentes, sendo que a Universidade de São Paulo (USP) foi a que apresentou o maior número de autores (26), seguida pela Universidade de Brasília (UnB), com 22 autores (Tabela 5).

A Tabela 6 apresenta a ocupação profissional dos autores.

Tabela 6 - Distribuição dos autores quanto a profissão

\begin{tabular}{c|c|c}
\hline Ocupação & $\mathbf{N}^{\mathbf{0}}$ de autores & $\mathbf{\%}$ \\
\hline Estudante & 99 & 32,14 \\
\hline Professor & 182 & 59,09 \\
\hline Servidor Público & 27 & 8,77 \\
\hline TOTAL & $\mathbf{3 0 8}$ & $\mathbf{1 0 0}$ \\
\hline
\end{tabular}

Fonte: Elaborada pelos autores.

Observa-se o domínio de professores na autoria dos artigos publicados, totalizando $59,09 \%$ dos autores, enquanto estudantes de graduação e pós-graduação representaram 32,14\% e servidores públicos apenas $8,77 \%$ (Tabela 6).

Conforme Oliveira (2002), as razões para o predomínio de professores na produção científica são muitas, entre elas, o fato de algumas universidades incentivarem seus professores a realizarem trabalhos científicos em troca de progressão funcional, incentivos salariais, prestígio na comunidade científica, entre outros.

A Tabela 7 apresenta os autores mais prolíficos na área de contabilidade governamental, entre os artigos pesquisados, e suas afiliações institucionais.

Tabela 7 - Ranking dos autores mais prolíficos na área governamental

\begin{tabular}{c|l|c|c}
\hline Ranking & \multicolumn{1}{|c|}{ Autor } & $\mathbf{N}^{\mathbf{0}}$ de artigos & Afiliações Institucionais \\
\hline \multirow{2}{*}{$1^{\text {o }}$} & Valmor Slomski & 10 & USP \\
\hline \multirow{2}{*}{$2^{\circ}$} & Lino Martins da Silva & 8 & UERJ \\
\cline { 2 - 4 } & Maurício Corrêa da Silva & 8 & UFRN \\
\hline \multirow{2}{*}{$3^{\text {o }}$} & José Francisco Ribeiro Filho & 7 & UFPE \\
\hline $4^{\circ}$ & Gilmar Ribeiro de Mello & 6 & UNIOESTE \\
\hline
\end{tabular}

R. Cont. Ufba, Salvador-Ba, v. 7, n. 2, p. 22-37, maio-agosto 2013 


\begin{tabular}{c|l|c|c}
\hline & Jorge Expedito de Gusmão Lopes & 6 & UFPE \\
\hline \multirow{2}{*}{$5^{\circ}$} & Marcleide Maria Macedo Pederneiras & 5 & UFPB \\
\hline \multirow{3}{*}{$6^{\circ}$} & Flávio da Cruz & 4 & UFSC \\
\cline { 2 - 4 } & Maria da Conceição da Costa Marques & 4 & $\begin{array}{c}\text { Instituto Superior de } \\
\text { Contabilidade de Coimbra }\end{array}$ \\
\hline \multirow{3}{*}{$7^{\circ}$} & Claudia Ferreira Cruz & 3 & UFRJ \\
\cline { 2 - 4 } & Luiz João Corrar & 3 & USP \\
\cline { 2 - 4 } & Patrícia Siqueira Varela & 3 & USP \\
\hline
\end{tabular}

Fonte: Elaborada pelos autores.

De acordo com os dados apresentados na Tabela 7, verifica-se que entre os 308 autores que figuram entre os 152 artigos analisados, a primeira posição do ranking é ocupada por Valmor Slomski da Universidade de São Paulo com 10 publicações, seguido por Lino Martins da Silva da Universidade Estadual do Rio de Janeiro e Maurício Corrêa da Silva com 8 artigos publicados. Vale ressaltar que merece destaque a USP com 3 autores no ranking, totalizando 16 publicações e a UFPE com 2 autores que representam um total de 13 artigos publicados.

A Tabela 8 apresenta a quantidade de referências que cada revista consultada apresenta e o número médio de obras por artigo de cada periódico. Foram considerados todos os tipos de referências, como livros, artigos, revistas, jornais, web sites, entre outros.

Tabela 8 - Número médio de referências por artigo

\begin{tabular}{|c|c|c|c|}
\hline Nome do Periódico & $\mathbf{N}^{0}$ de artigos & $\begin{array}{l}\mathrm{N}^{\mathbf{o}} \text { de } \\
\text { referências }\end{array}$ & $\begin{array}{c}\mathbf{N}^{0} \text { médio de referências por } \\
\text { artigo }\end{array}$ \\
\hline Revista de Administração Pública & 17 & 511 & 30,06 \\
\hline RAE Eletrônica & 2 & 23 & 11,50 \\
\hline $\begin{array}{l}\text { Revista de Administração } \\
\text { Contemporânea }\end{array}$ & 6 & 122 & 20,33 \\
\hline $\begin{array}{l}\text { Revista de Administração Mackenzie - } \\
\text { RAM }\end{array}$ & 0 & 0 & 0,00 \\
\hline Revista de Contabilidade \& Finanças & 5 & 112 & 22,40 \\
\hline Revista de Contabilidade e Organizações & 5 & 157 & 31,40 \\
\hline Revista Contemporânea de Contabilidade & 8 & 178 & 22,25 \\
\hline $\begin{array}{l}\text { Revista de Educação e Pesquisa em } \\
\text { Contabilidade }\end{array}$ & 9 & 186 & 20,67 \\
\hline Contabilidade Vista \& Revista & 14 & 240 & 17,14 \\
\hline Revista Universo Contábil & 11 & 298 & 27,09 \\
\hline $\begin{array}{l}\text { Contextus - Revista Contemporânea de } \\
\text { Economia e Gestão }\end{array}$ & 1 & 14 & 14,00 \\
\hline Pensar Contábil & 7 & 149 & 21,29 \\
\hline Revista Análise & 3 & 46 & 15,33 \\
\hline $\begin{array}{l}\text { Revista de Contabilidade do Mestrado } \\
\text { em Ciências Contábeis da UERJ }\end{array}$ & 8 & 211 & 26,38 \\
\hline Revista de Informação Contábil & 7 & 122 & 17,43 \\
\hline Revista Economia \& Gestão & 4 & 110 & 27,50 \\
\hline Revista Produção Online & 1 & 30 & 30,00 \\
\hline Enfoque: Reflexão Contábil & 10 & 170 & 17,00 \\
\hline Contabilidade, Gestão e Governança & 19 & 415 & 21,84 \\
\hline
\end{tabular}




\begin{tabular}{l|c|c|c} 
Contexto & 7 & 210 & 30,00 \\
\hline Ciências Sociais Aplicadas em Revista & 1 & 6 & 6,00 \\
\hline Revista Ambiente Contábil & 3 & 70 & 23,33 \\
\hline Revista de Contabilidade da UFBA & 4 & 78 & 19,50 \\
\hline Revista Gestão Organizacional & 0 & 0 & 0,00 \\
\hline \multicolumn{1}{c|}{ Totais } & $\mathbf{1 5 2}$ & $\mathbf{3 4 5 8}$ & $\mathbf{2 2 , 7 5}$ \\
\hline
\end{tabular}

Fonte: Elaborada pelos autores

Com base na análise da Tabela 8 , observa-se que o número médio de referências utilizadas pelos 152 artigos pesquisados foi de 22,75. A Revista de Contabilidade e Organizações foi o periódico que apresentou a maior média de referências por artigo, que correspondeu a 31,40, seguida pela Revista de Administração Pública com 30,06 referências por artigo. A menor média de referências por artigo encontrada foi do periódico Ciências Sociais Aplicadas em Revista com uma média de 6 obras por artigo. Esse resultados demonstram que os autores têm utilizado uma média baixa de referências no embasamento de seus artigos.

A origem das 3458 referências utilizadas nos 152 artigos analisados pode ser observada na Tabela 9.

Tabela 9 - Origem das referências dos artigos pesquisados

\begin{tabular}{|c|c|c|c|}
\hline \multirow{2}{*}{ Nome do Periódico } & \multicolumn{3}{|c|}{ Origem das referências } \\
\hline & Nacionais & Internacionais & Total \\
\hline Revista de Administração Pública & 329 & 182 & 511 \\
\hline RAE Eletrônica & 23 & 0 & 23 \\
\hline Revista de Administração Contemporânea & 56 & 66 & 122 \\
\hline $\begin{array}{l}\text { Revista de Administração Mackenzie - } \\
\text { RAM }\end{array}$ & 0 & 0 & 0 \\
\hline Revista de Contabilidade \& Finanças & 75 & 37 & 112 \\
\hline Revista de Contabilidade e Organizações & 88 & 69 & 157 \\
\hline Revista Contemporânea de Contabilidade & 165 & 13 & 178 \\
\hline $\begin{array}{l}\text { Revista de Educação e Pesquisa em } \\
\text { Contabilidade }\end{array}$ & 132 & 54 & 186 \\
\hline Contabilidade Vista e Revista & 229 & 11 & 240 \\
\hline Revista Universo Contábil & 225 & 73 & 298 \\
\hline $\begin{array}{l}\text { Contextus - Revista Contemporânea de } \\
\text { Economia e Gestão }\end{array}$ & 13 & 1 & 14 \\
\hline Pensar Contábil & 119 & 30 & 149 \\
\hline Revista Análise & 41 & 5 & 46 \\
\hline $\begin{array}{l}\text { Revista de Contabilidade do Mestrado em } \\
\text { Ciências Contábeis da UERJ }\end{array}$ & 190 & 21 & 211 \\
\hline Revista de Informação Contábil & 117 & 5 & 122 \\
\hline Revista Economia \& Gestão & 71 & 39 & 110 \\
\hline Revista Produção Online & 22 & 8 & 30 \\
\hline Enfoque: Reflexão Contábil & 166 & 4 & 170 \\
\hline Contabilidade, Gestão e Governança & 367 & 48 & 415 \\
\hline Contexto & 161 & 49 & 210 \\
\hline Ciências Sociais Aplicadas em Revista & 6 & 0 & 6 \\
\hline
\end{tabular}




\begin{tabular}{c|c|c|c} 
Revista Ambiente Contábil & 70 & 0 & 70 \\
\hline Revista de Contabilidade da UFBA & 77 & 1 & 78 \\
\hline Revista Gestão Organizacional & 0 & 0 & 0 \\
\hline \multicolumn{1}{c|}{ Totais } & $\mathbf{2 7 4 2}$ & $\mathbf{7 1 6}$ & $\mathbf{3 4 5 8}$ \\
\hline
\end{tabular}

Fonte: Elaborada pelos autores.

De acordo com análise da Tabela 9, verifica-se que houve predomínio da literatura nacional em detrimento a estrangeira nas referências dos artigos analisados, com 2.742 referências, que representa um percentual de $79,29 \%$ contra $20,71 \%$ das 716 referências estrangeiras. Observase ainda que os periódicos que apresentam um maior número de referências estrangeiras em seus artigos são aquelas que possuem melhor classificação no Qualis da CAPES.

As palavras-chaves mais relevantes tratados nos artigos analisados, referente à contabilidade governamental estão apresentados na Tabela 10 abaixo:

Tabela 10 - Os quinze temas mais abordados nos artigos pesquisados

\begin{tabular}{c|c}
\hline Palavras-chave & $\mathbf{N}^{\mathbf{o}}$ de artigos \\
\hline Contabilidade Pública & 27 \\
\hline Administração Pública & 23 \\
\hline Orçamento Público & 15 \\
\hline Transparência & 14 \\
\hline Lei de Responsabilidade Fiscal & 13 \\
\hline Finanças Públicas & 11 \\
\hline Gestão Pública & 8 \\
\hline Accountability & 8 \\
\hline Controle Interno & 7 \\
\hline Receita Pública & 6 \\
\hline Tribunal de Contas & 6 \\
\hline Contas Públicas & 5 \\
\hline Custos & 5 \\
\hline Evidenciação & 4 \\
\hline Prestação de Contas & 4 \\
\hline
\end{tabular}

Fonte: Elaborada pelos autores.

Diante dos resultados expostos na Tabela 10, percebe-se que contabilidade pública foi o assunto mais referenciado nas palavras-chaves das publicações pesquisadas, com 27 artigos, seguido por administração pública com 23 , orçamento público com 15 , transparência em 14 e lei de responsabilidade fiscal em 13. Observa-se por esses resultados que os temas utilizados nos artigos pesquisados são bem diversificados, mas não fogem do tema central que corresponde à contabilidade do setor público.

\section{CONSIDERAÇÕES FINAIS, RECOMENDAÇÕES E CONCLUSÃO}

A pesquisa, em atenção ao objetivo formulado, analisou a produção científica da contabilidade governamental nos periódicos que utilizam o SEER e o SciELO. A divulgação de estudos 
bibliométricos na área da contabilidade tem aumentado nos últimos anos. Tais estudos proporcionam ao pesquisador contábil identificar com rapidez os periódicos, os autores, as instituições etc., que divulgam temas relacionados com o seu objeto de pesquisa.

As discussões acadêmicas e as devidas publicações em periódicos sobre a contabilidade proporcionam desenvolvimento para a ciência contábil. No caso da contabilidade governamental, deve-se ressaltar, ainda, que tais estudos podem orientar os seus usuários potenciais (os cidadãos) a tomarem decisões por ocasião das eleições de seus representantes.

Tendo em vista a delimitação da presente pesquisa no estudo bibliométrico dos periódicos que utilizam os sistemas SEER e SciELO, recomendam-se outras pesquisas para que seja verificada a produção sobre a contabilidade governamental utilizando outras amostras de estudo, tais como: livros, periódicos impressos, periódicos com acesso por assinatura mediante retribuição, anais de congressos, dissertações, teses etc.

A produção científica na área da contabilidade governamental, nos periódicos analisados, ainda é escassa (média de 5,39\% dos artigos analisados).

Conclui-se, finalmente, que nas 564 edições analisadas foram encontrados 152 artigos relacionados com a contabilidade governamental. Os periódicos que mais publicaram dos consultados foram: Contabilidade, Gestão e Governança com 19 artigos, Revista de Administração Pública com 17, Revista Universo Contábil com 11 e Enfoque: Reflexão Contábil com 10 publicações. Houve o predomínio de autores professores do sexo masculino, com titulação de doutor que mais publicaram. A Universidade de São Paulo (USP) seguida da Universidade de Brasília (UnB) foram as instituições que apresentaram o maior número de autores com artigos publicados. Quanto às referências, foram mais utilizadas as brasileiras e que os periódicos que apresentam o maior número de referências estrangeiras em seus artigos são as que possuem melhor classificação no Qualis da CAPES.

\section{REFERÊNCIAS}

ALVARENGA, Lídia. Bibliometria e arqueologia do saber de Michel Foucault: traços de identidade teórico-metodológica. Ciência da Informação, Brasília, v. 27, n.3, p. 1-9, set./dez. 1998.

ARAÚJO, Carlos Alberto. Bibliometria: evolução histórica e questões atuais. Em Questão, Porto Alegre, v. 12, n. 1, p. 11-32, jan./jun. 2006.

BARBOSA, Glauber de Castro; BARROS, Fabrício de Oliveira. O perfil dos autores na produção científica em contabilidade: o caso do congresso USP de controladoria e contabilidade e do congresso ANPCONT. Enfoque: Reflexão Contábil, Maringá, v. 29, n. 3, p. 22-33, set./dez. 2010.

BARBOSA, Daiane dos Santos; QUINTANA, Alexandre Costa; MACHADO, Débora Gomes. Análise da Produção Científica sobre os fluxos de caixa e a demonstração dos fluxos de caixa: um estudo da Revista de Contabilidade \& Finanças da Universidade de São Paulo, no período de 1989 a 2009. Enfoque: Reflexão Contábil, Maringá, v. 30, n.2, p. 52-66, mai/ago. 2011.

BEUREN, Ilse Maria (Org.). Como elaborar trabalhos monográficos em contabilidade: teoria e prática. São Paulo: Atlas, 2003. 
BEZERRA FILHO, João Eudes. Contabilidade Pública: teoria e técnica de elaboração de balanços e 300 questões. Niterói : Impetus, 2004.

BRASIL. Lei n ${ }^{\circ} 4.320$, de 17 de março de 1964. Estatui normas gerais de direito financeiro para elaboração e controle dos orçamentos e balanços da União, Estados, Municípios e do Distrito Federal. Diário Oficial [da] República Federativa do Brasil, Brasília, DF, 23 de março de 1964.

BRASIL. Ministério da Fazenda. Portaria n ${ }^{\circ}$ 184, de 25 de agosto de 2008. Dispõe sobre as diretrizes a serem observadas no setor público (pelos entes públicos) quanto aos procedimentos, práticas, elaboração e divulgação das demonstrações contábeis, de forma a torná-los convergentes com as Normas Internacionais de Contabilidade Aplicadas ao Setor Público. Diário Oficial [da] República Federativa do Brasil, Brasília, DF, 26 de agosto de 2008.

BRASIL. Ministério da Ciência e Tecnologia. Instituto Brasileiro de Informação em Ciência e Tecnologia (IBICT). Portal do Sistema Eletrônico de Editoração de Revistas (SEER). Disponível em: <http://seer.ibict.br/index.php?option=com_frontpage\&Itemid=1>. Acesso em: 29 set. 2011.

CARDOSO, Ricardo Lopes et al. Pesquisa Científica em Contabilidade entre 1990 e 2003. RAE. Revista de Administração de Empresas, São Paulo, v. 45, p. 34-45, 2005.

HAIDAR, Suelen Ronchi. Análise da Produção Científica Docente de um Programa de PósGraduação: o Caso do PPGC/UFSC. In: ASSOCIAÇÃO NACIONAL DOS CURSOS DE GRADUAÇÃ̃ EM ADMINISTRAÇÃO, 19, 2008, Curitiba. Anais... Curitiba: EnANGRAD, 2008. CD-ROM.

KOHAMA, Helio. Contabilidade Pública: teoria e prática. 9. ed. São Paulo : Atlas, 2003.

LEITE FILHO, Geraldo Alemandro; SIQUEIRA, Regina Lacerda. Revista de Contabilidade \& Finanças USP: uma análise bibliométrica de 1999 a 2006. Revista de Informação Contábil, Recife, v. 1, n. 2, out/dez. 2007.

MARTINS, Gilberto de Andrade; THEÓPHILO, Carlos Renato. Metodologia da investigação científica para ciências sociais aplicadas. 2. ed. São Paulo: Atlas, 2009.

NORONHA, Daisy Pires; KIYOTANI, Normanda Miranda; JUANES, Ivone Soares. Produção científica em comunicação dos docentes da ECA/USP. In: CONGRESSO BRASILEIRO DE CIÊNCIAS DA COMUNICAÇÃO. Anais ... 2002. Salvador: Congresso Brasileiro de Ciências da Comunicação, 2002.

OLIVEIRA, Marcelle Colares. Análise dos Periódicos Brasileiros de Contabilidade. Revista Contabilidade \& Finanças - USP, São Paulo, n. 29, p. 68 - 86, maio/ago. 2002.

PERDIGÃO, Laura Zuza; NIYAMA, Jorge Katsumi; SANTANA, Claudio Moreira. Contabilidade, Gestão e Governança: análise de doze anos de publicação (1998 a 2009). Contabilidade, Gestão e Governança, Brasília, v. 13, n. 3, set/dez 2010. 
PISCITELLI, Roberto Bocaccio; TIMBÓ, Maria Zulene Farias; ROSA, Maria Berenice. Contabilidade pública: uma abordagem da administração financeira pública. 7. ed. São Paulo: Atlas, 2002.

PISCITELLI, Roberto Bocaccio; TIMBÓ, Maria Zulene Farias. Contabilidade pública: uma abordagem da administração pública. 11 ed. São Paulo: Atlas, 2010.

PONTE, Vera Maria Rodrigues et al. Análise das Metodologias e Técnicas de Pesquisa adotadas nos estudos brasileiros sobre Balanced Scorecard: um estudo dos artigos publicados no período de 1999 a 2006. In: I CONGRESSO ANPCONT, 2007, Anais... Gramado, 2007.

REIS, Luciano Gomes et al. A pesquisa brasileira em contabilidade do setor público: uma análise após a implementação da lei de responsabilidade fiscal. Revista de Informação Contábil, Recife, v 1, n. 1, set. 2007.

REIS, Heraldo da Costa; MACHADO JÚNIOR, José Teixeira. A lei 4.320 comentada e a lei de responsabilidade fiscal. 33 ed. Rio de Janeiro: Lumen Juris, IBAM, 2010.

ROSA, Aglaenne Flávia da et al. Earnings management no Brasil: uma análise sob a perspectiva sociométrica e bibliométrica. Contabilidade Vista \& Revista, Belo Horizonte, v. 21, n. 4, p. 177-206, out./dez. 2010.

SANTANA, Cláudio Moreira. Produção do conhecimento em contabilidade social no Brasil (1990 a 2003): uma abordagem bibliométrica. Dissertação (Mestrado em Controladoria e Contabilidade). Programa de Pós-Graduação em Ciências Contábeis, FEA/USP, São Paulo, 2004.

Scientific Electronic Library Online (SciELO). FAPESP - BIREME. São Paulo. Disponível em: <http://www.scielo.br/?lng=pt>. Acesso em: 29 set. 2011.

SILVA, Lino Martins da. Contabilidade governamental: um enfoque administrativo. 5 ed. São Paulo: Atlas, 2002.

SOUZA, Flávia Cruz et al. Análise das IES da Área de Ciências Contábeis e de seus Pesquisadores por meio de sua Produção Científica. Contabilidade Vista \& Revista, Belo Horizonte, v. 19, n. 3, p. 15-38, jul./set. 2008.

THEÓPHILO, Carlos Renato; IUDÍCIBUS, Sérgio de. Uma Análise Crítico-Epistemológica da Produção Científica em Contabilidade no Brasil. Contabilidade, Gestão e Governança, Brasília, v. 8, n. 2, jul./dez. 2005. 